\title{
TRUE HEARTH LINING WEAR AS BLAST FURNACE CAMPAIGN EXTENSION TOOL*
}

\author{
Jean-Philippe Houde ${ }^{1}$ \\ Rudolf $\mathrm{Hebel}^{2}$ \\ André Cabral de Oliveira ${ }^{3}$
}

\begin{abstract}
The Blast Furnace Campaign lifetime is highly depending on the wear progress of the hearth lining. This progress is monitored in general through single and double thermocouples at the cold side of the lining. This type of monitoring becomes ineffective as soon as heat resistance will be formed in the refractory lining. Paul Wurth's monitoring system, consisting of MTP-Sensor and Heat Flux Probes, is able to identify such heat resistances to give a true hearth lining wear. Since last year Paul Wurth is also able to install safely those MTP-Sensor and Heat Flux Probes on running blast furnace without salamander tapping, thanks to a newly developed cooled core drilling device. Blast Furnaces that are equipped with Paul Wurth's monitoring system have optimized their campaign lifetime as they received right information upon the true wear lining such as detection of heat flux transfer failure, detection and monitoring of brittle layer or detection of hot spot.

Keywords: Hearth refractory's wear observation and monitoring; Heat resistance detection; Safe core drilling without salamander tapping; Hot metal resistant sensor probe installation.
\end{abstract}

1 Master Degree in Chemistry, Head of Department, Blast Furnace and Direct Reduction, Paul Wurth Refractory \& Engineering, Mainz-Kastel, Germany.

2 Mechanical Engineer, Consultant, Blast Furnace and Direct Reduction, Paul Wurth Refractory \& Engineering, Mainz-Kastel, Germany.

3 Metallurgical Technician graduated in System Analysis IT, Sales Coordinator, Marketing and Sales, Paul Wurth do Brasil, Belo Horizonte, Minas Gerais, Brazil. 


\section{INTRODUCTION}

As the hearth refractory lining has a direct influence on the campaign lifetime of a blast furnace, it is of utmost interest monitoring it in a proper matter. The most spread way consists of a temperature difference analysis using twin thermocouples at the cold side of the lining. The input requested parameters are fixed at the beginning of the BF-campaign, like thermal conductivity of the different refractory material, and are taken for granted during the whole campaign lifetime. Unfortunately those input parameters will evolve with the time due to infiltration, to the apparition of heat resistance or of brittle layer formations, leading to wrong hearth lining wear analysis. In the last decades, Paul Wurth developed its own temperature measuring system called MTP-Sensor Probes, easy to install and breakthrough resistance, allowing the follow up of the input parameters and adjusting its temperature analysis to reach the true hearth lining wear. This system has been implemented successfully in many different blast furnaces and, since last year, the newly developed safety cooling drilling device has permitted the implementation of MTP-Sensor Probes on running blast furnaces without salamander tapping.

The knowledge of the true hearth lining wear, gained by the Paul Wurth's MTP monitoring servicing, has been helpful to detect advanced spot wear, brittle layer formations and to follow up their evolution. Through this tool, blast furnace operators received the right information to decide upon the blast furnace campaign lifetime and its possible extension.

\section{TRUE HEARTH LINING WEAR}

The temperature monitoring of the hearth refractory lining is a worldwide well-known analysis consisting in the measurement of the temperature difference between thermocouples, combined with the knowledge of the thermal conductivity of the refractory material enables, through linear iteration, to determine the hearth lining wear. The figure 1 shows the wear calculation results of such analysis.

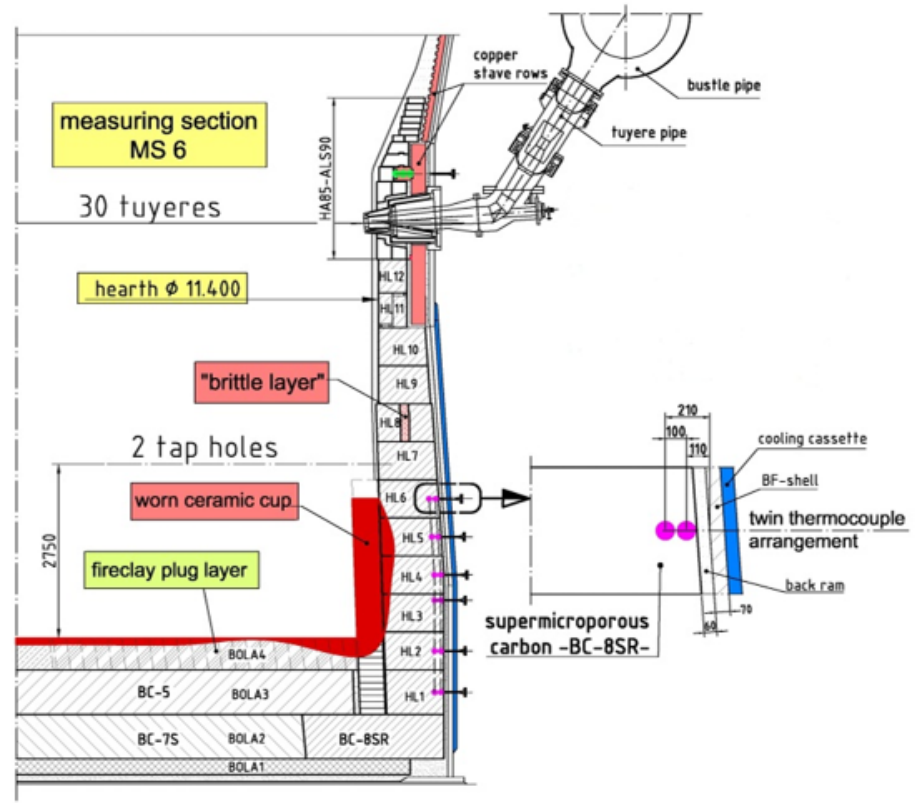

Figure 1. Hearth Lining Wear Analysis Observed by Double Thermocouples. 
This analysis gives the true hearth lining wear at the beginning of the blast furnace campaign and until no alterations appears inside the hearth lining refractory.

\subsection{Influence of Thermal Conductivity}

One of the requested input parameters to perform a wear analysis is the thermal conductivity of the different installed refractory material. The Thermocouple (TC) is defined according laboratory testing on new material. The refractory in the hearth is however submitted to external constrains, like alkalis, zinc oxide a.o., which can infiltrate inside the material matrix and modify the thermal conductivity.

The core probe drilling performed by Paul Wurth on running blast furnaces to investigate the thermal conductivity behavior of the refractory material with time reveals a strong modification of the thermal conductivity. Figure 2 shows the TC modification of a core probe taken in the hearth side wall after ten years of running BF-campaign.

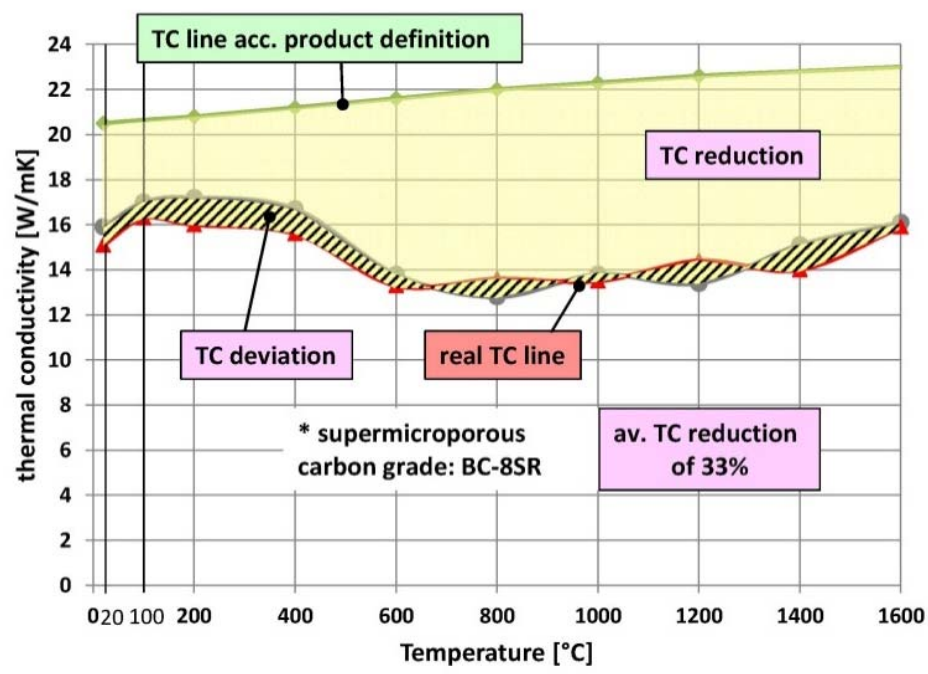

Figure 2. TC Deviation of Carbon Material after 10 Years of Running BF-Campaign

The results show a strong TC reduction of $33 \%$ with a minor TC deviation on the real TC line, which is not always the case. Such modification has, of course, a direct impact on wear analysis.

\subsection{Influence of Heat Resistances}

Additionally to the alkalis and zinc oxide infiltration, which can lead to embrittled lining structures, the hearth refractory is submitted to thermomechanical stress and strain that can lead to joint opening or to cracks in the refractory material. Those modifications of the initial lining state, called heat resistances, will disturb the heat transfer. The figure 3 shows the impact of an undetermined brittle layer on the wear analysis. 


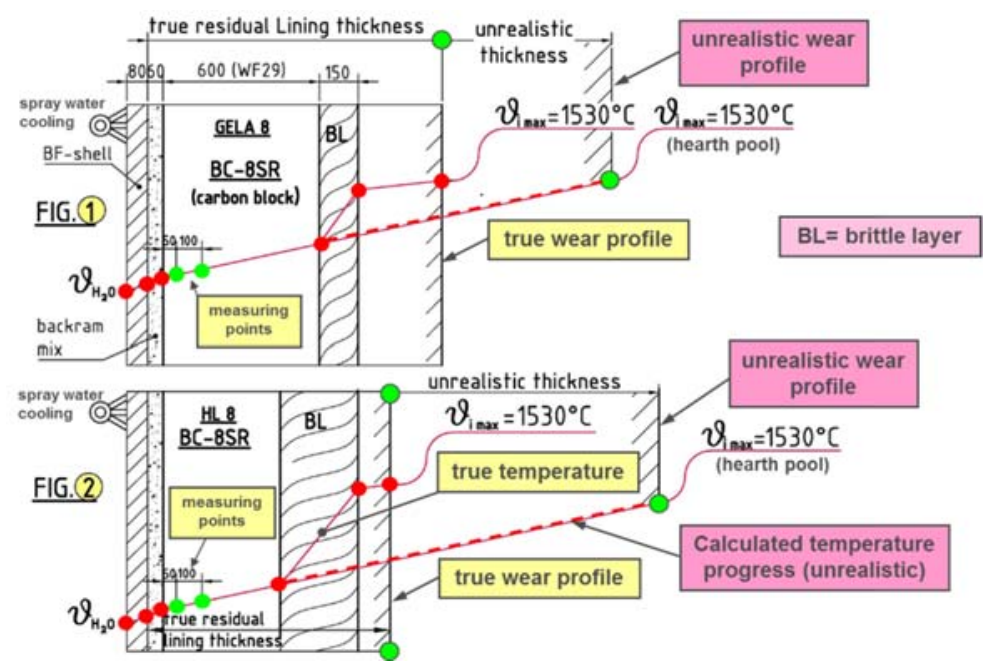

Figure 3. Impact of a Brittle Layer Formation in the Hearth Lining

It becomes then obvious that the true hearth lining wear cannot be calculate without the determination of all alterations of the refractory material during the BF-campaign.

\section{MTP-SENSOR AND HEAT FLUX PROBE}

In the last decades, Paul Wurth has developed and optimized its MTP-Sensor and Heat Flux Probe to compensate the temperature reading failures and access the true hearth lining wear. The figure 4 shows schematically a MTP-Sensor and Heat Flux Probe.

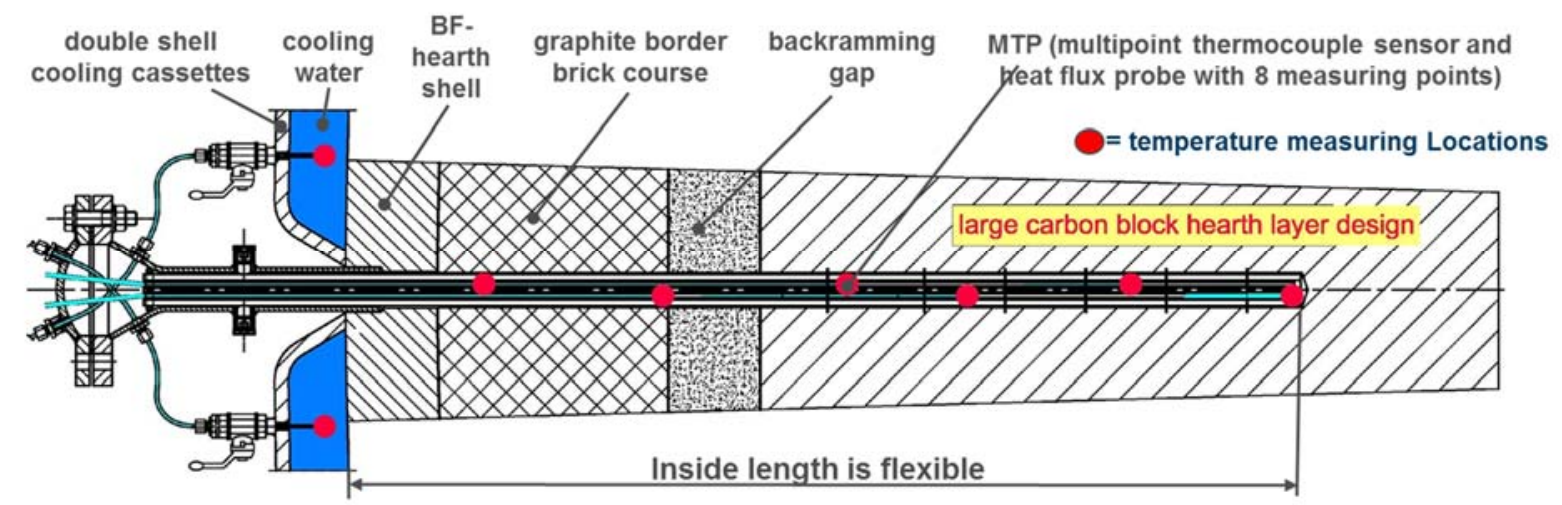

Figure 4. Schematic MTP-Sensor and Heat Flux Probe

The hot metal breakthrough resistant, engineered MTP-Sensor and Heat Flux Probe has become now a well experienced system that can newly be installed on running blast furnace without salamander tapping.

\subsection{Installation of MTP-Sensor and Heat Flux Probe on Running Blast Furnace}

Paul Wurth developed a safety pilot drilling procedure with an extremely chilled cooling and drilling device that permits to drill deep into the residual hearth lining during the whole running campaign.

The efficiency and optimization has been first tested in a special laboratory test rig as shown on figure 5 . 


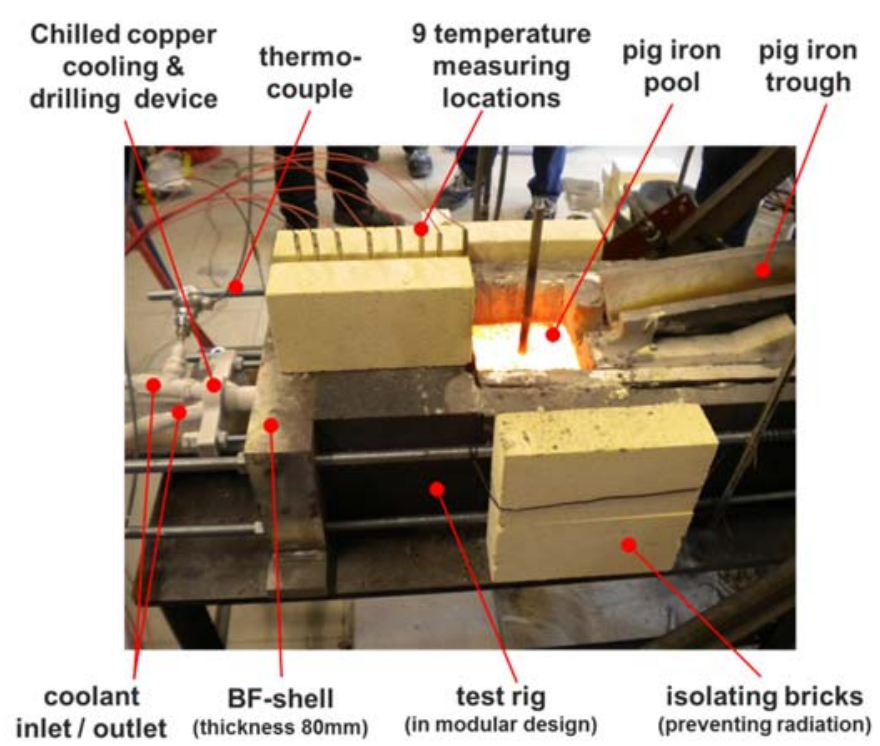

Figure 5. Liquid Pig Iron Test of the Special Cooled Drilling Device

Once optimized, the safety pilot drilling system have been tested on running blast furnaces without salamander tapping as shown on figure 6.

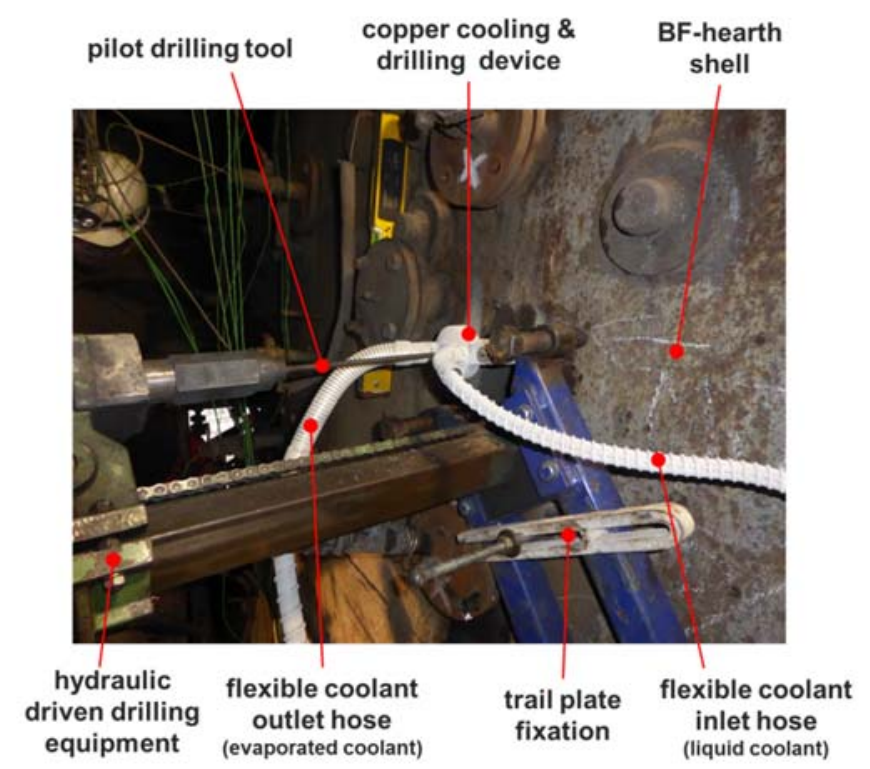

Figure 6. Safety Pilot Drilling Work on BF-Hearth Side Wall

In the meantime, MTP-Sensor and Heat Flux Probes have been successfully installed on four different blast furnaces in Germany without salamander tapping.

\section{BF-CAMPAIGN EXTENSION TOOLS}

The MTP monitoring and observation management is able to identify the before mentioned alteration of the hearth refractory lining enabling to reach the true hearth lining wear in the measured hearth sections. 


\subsection{Heat Resistance Management}

Additionally to the temperature, the heat flux observation is essential as shown on figure 7 .

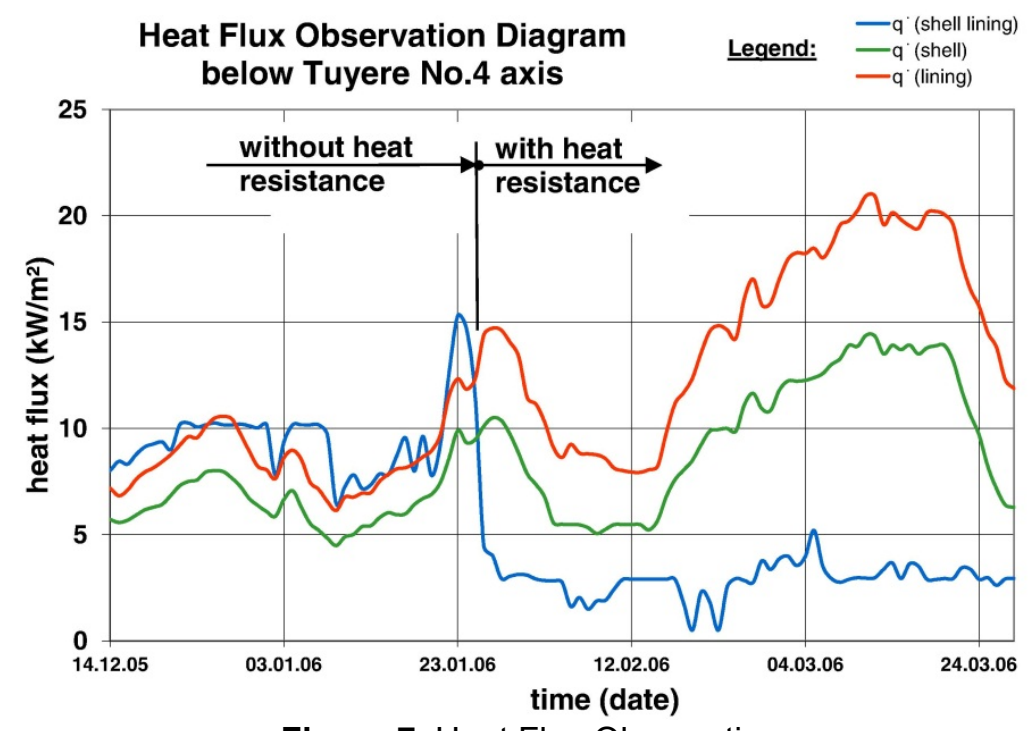

Figure 7. Heat Flux Observation

The evolution of the measured and calculated heat fluxes shows here the detection of a heat resistance formation. Once it has been formed, it is necessary to observe and to follow up the heat resistance. The figure 8 shows an example of heat resistance observation.

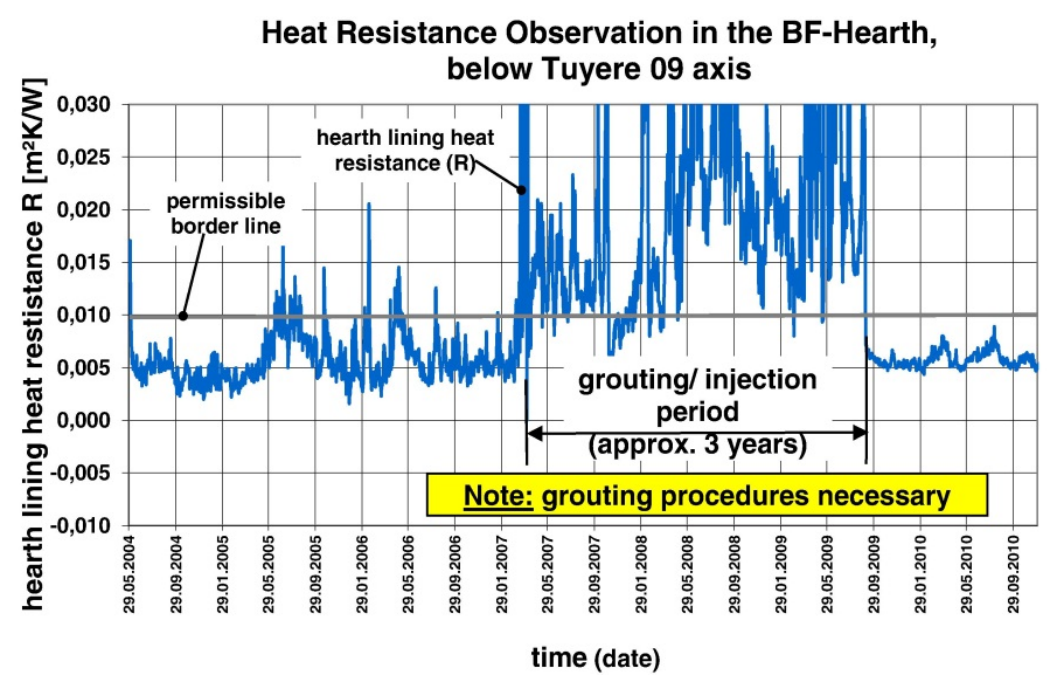

Figure 8. Heat Resistance Observation and its Countermeasure

The observation shows that the heat resistance has exceeded the permissible border and grouting work was necessary. Three years with different grouting actions have been needed to reduce the heat resistance back to an acceptable level. 


\subsection{Hot Spot Detection}

The knowledge of the true hearth lining wear allows to identify hot spot formations early enough to avoid critical residual lining thicknesses or break outs. The figure 9 shows an example of hot spot detection just before a breakthrough.

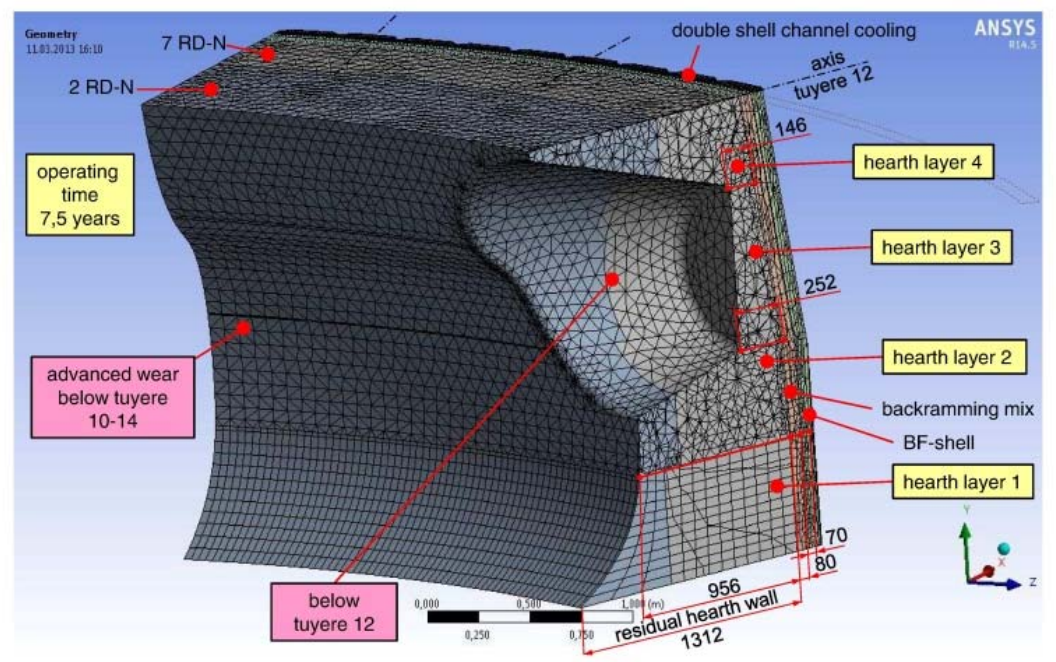

Figure 9. 3D Hot Spot Wear Calculation

Once the hot spot have been detected, it has been monitored more accurately with a number of additional heat flux probes, stress measuring gauges, TC probes and MTP-probes until the foreseen repair as shown on figure 10.

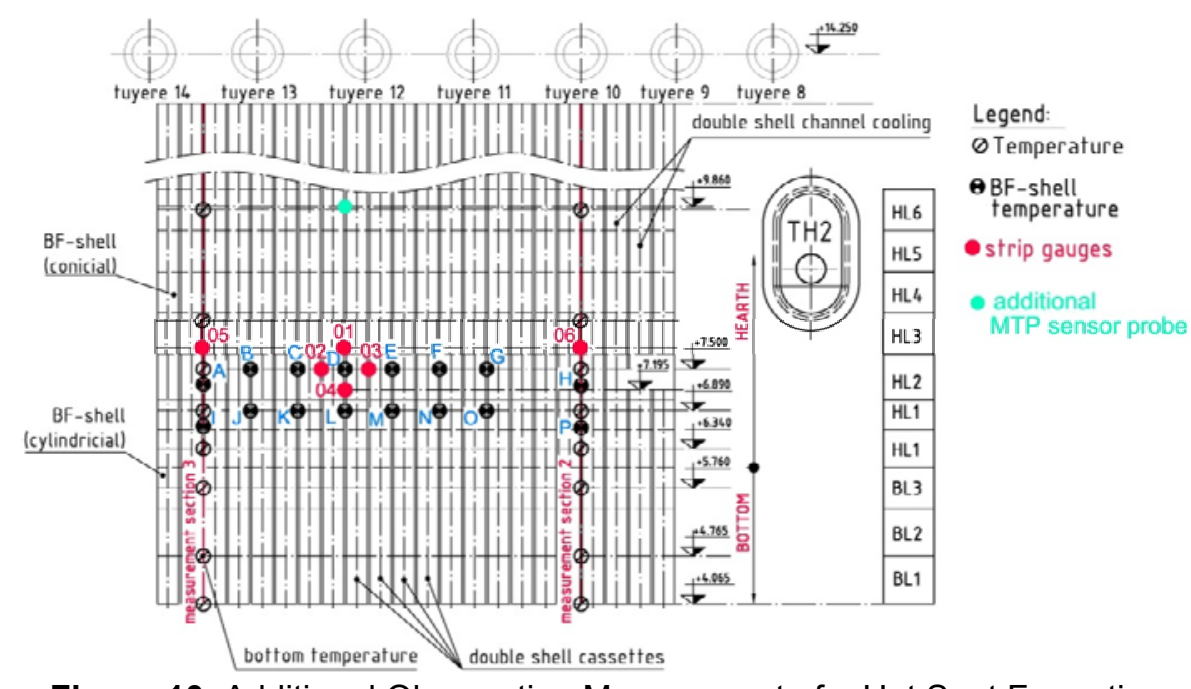

Figure 10. Additional Observation Management of a Hot Spot Formation

The hearth lining repair shows that it was the right decision. Embrittled structure and brittle layer formation were observed in all hearth side wall layers as shown on figure 11. 


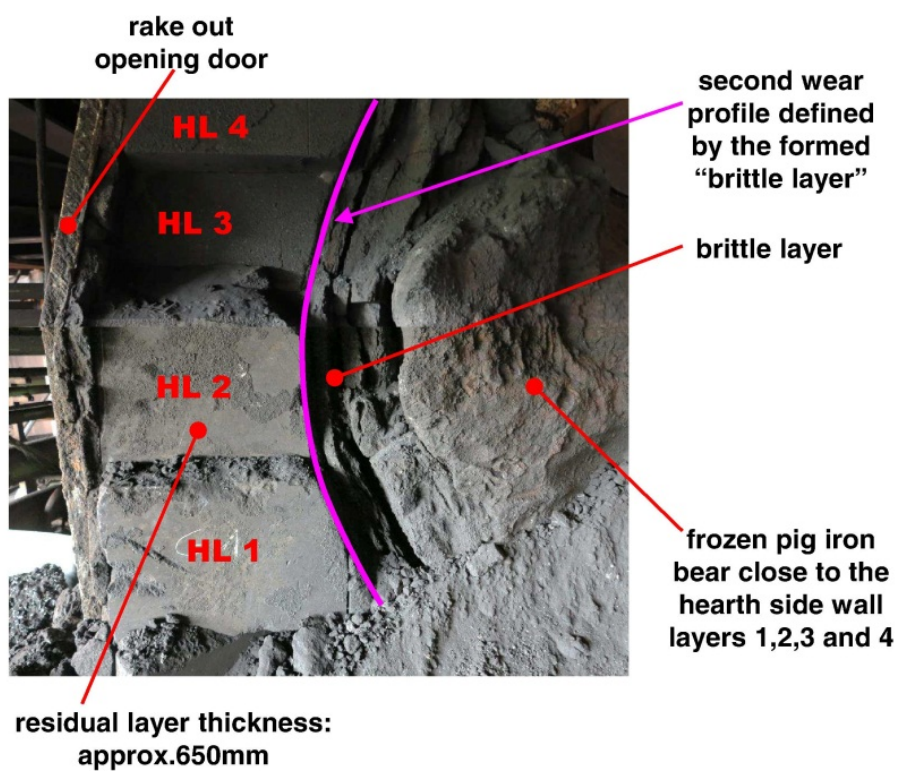

Figure 11. Hearth Side Wall Brittle Layer Formation

\subsection{Accession to the True Hearth Lining Wear}

The benefit of the PW-knowledge of the true hearth lining wear could be experimented on one of the running blast furnace that received additional MTPSensor and Heat Flux Probes. The installation was done with the safety cooling drilling device. Figure 12 shows the true hearth lining wear.

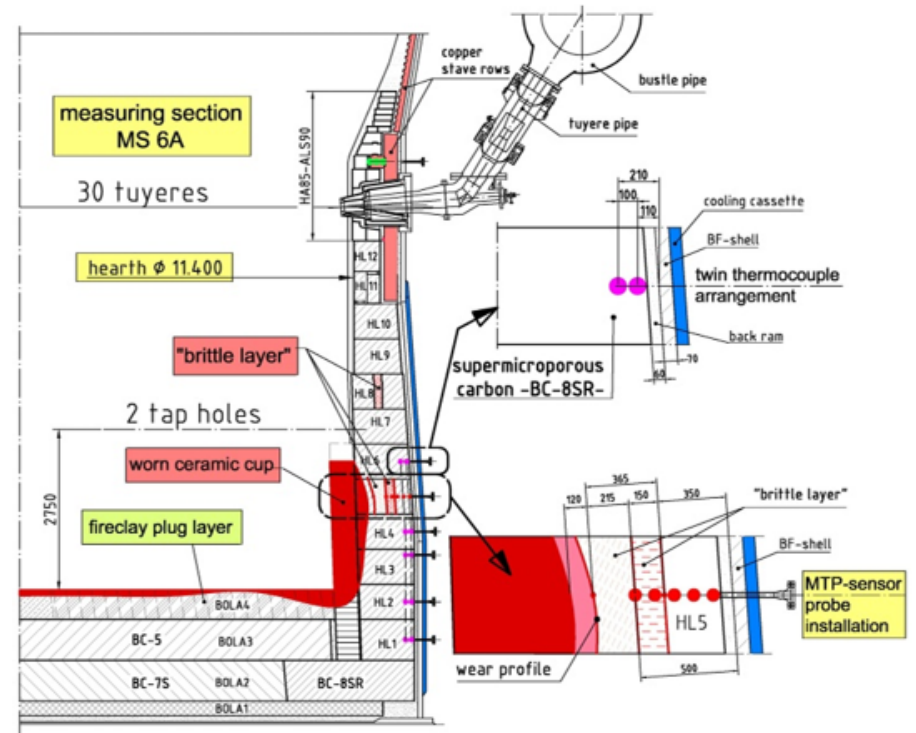

Figure 12. True Hearth Lining Wear

Compared to the hearth lining wear calculation performed before the installation of additional MTP-Sensor and Heat Flux Probes, the true hearth lining wear identify the embrittled zone, respectively the brittle layer. The BF condition was therefore worse than expected but an early identification enables the right follow-up. 


\subsection{Brittle Layer Management}

Once a brittle layer has been identified, it's progress towards the BF-shell have to be observed and followed up. The figure 13 shows the spreading behavior observation of the embrittled zone.

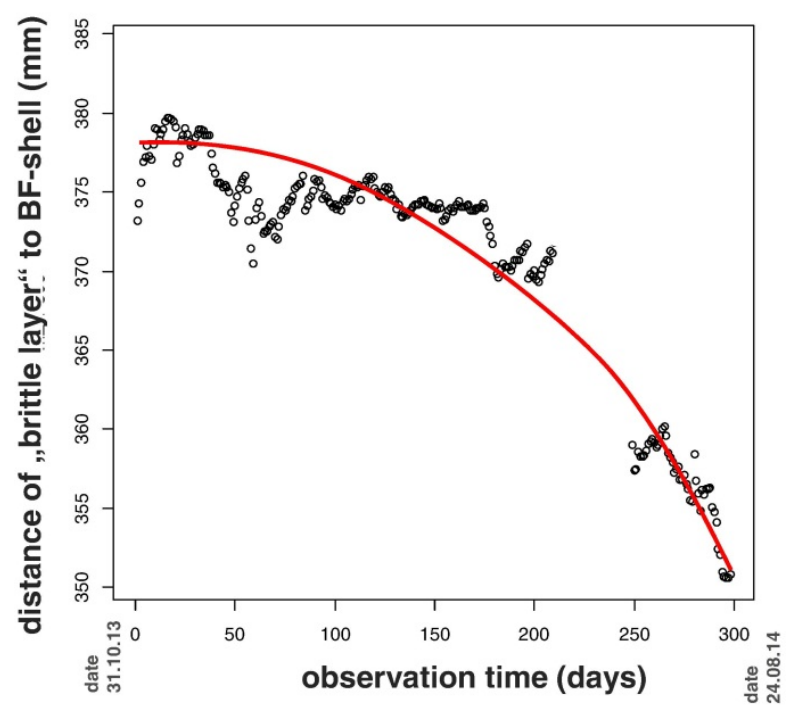

Figure 13. Spreading Behavior of an Embrittled Zone

The observed spreading rate of the embrittled zone towards the BF-shell was approximately $30 \mathrm{~mm} /$ year. This observation enables to validate the BF-campaign extension as foreseen.

\section{CONCLUSION}

The wear progress management based on the usual single and double thermocouple monitoring system can only give good result at the beginning of the BF campaign as far as the hearth lining refractory material has not been modified, assuming that the thermocouples worked correctly. The true hearth lining wear can only be reached if all type of alterations towards the hearth refractory material have been taken into account, such as heat resistance formation, thermal conductivity modification or brittle layer formation.

The newly developed safety pilot drilling work enables the installation of the now well experienced MTP-Sensor and Heat Flux Probes, on running blast furnaces without salamander tapping. This procedure has been successfully executed on four different German blast furnaces in the meantime.

The MTP monitoring and observation system is able to reach the true hearth lining wear and provide useful information such as detection of heat resistance, detection of hot spot, detection of embrittlement structures, which is an helpful tool to make a decision upon the expected BF campaign and its possible lifetime extension. 